\title{
Social Networking in Family Businesses in a Local Economy
}

Accepted for publication in Local Economy by SAGE. The final published version is available at https://doi.org/10.1177/0269094217722505

Dr Claire Seaman*, Professor Ronald McQuaid** and Dr Mike Pearson***

* Queen Margaret University

Edinburgh EH21 6UU

00441314470000

Email: cseaman@qmu.ac.uk

* Contact Author

** Stirling Management School

University of Stirling

Stirling FK9 4LA

*** Employment Research Institute

Edinburgh Napier University

Craiglockhart Campus

Edinburgh EH14 1DJ

\section{Social Networking in Family Businesses in a Local Economy}

\begin{abstract}
Small, family owned businesses make considerable contributions to local economies. The importance of social networks to their development is also well established. This paper explores the different types of distinct, but interlocking, social networks of a rural business family, focussing upon the interaction between family, business and friendship networks. It presents a multi-rational logic framework to consider how the differing logics of each of these network influences the development and behaviour of family businesses. The changes in networks over time and between generations of the family are also analysed and gaps or structural holes within the networks identified. Implications for research and policy are then set out.
\end{abstract}

\section{Keywords}

Family business, social networks, business networks, multi-rational perspective, longitudinal, local economy 


\section{Social Networking in Business Families in a Local Economy Introduction}

The contribution made by smaller, often family owned businesses to local economic development is well established. An important aspects of small family businesses that distinguishes them from other SMEs is the difference in their social networks, and how these operate, including the potential for a more complex web of relationships that can enable greater engagement with the environment in which the family business operates. These networks can act as bridges to outside sources of knowledge and expertise and hence to better exploitation of opportunities and innovation and the development or creation of new businesses (Fletcher, 2002; Gronum et al., 2012; Fayolle et al., 2016). However, the focus of most research on social networks has been on individual business entrepreneurs and with little research on the forms of networks that exist in families that are involved in one or more businesses. Further, the multiple rationalities of the family, business and friendship networks that coexist in families in business (Seaman et al., 2014, 2015) contribute to the context in which local economic development activity takes place (Seaman et al., 2016). This paper analyses the relationships between three types of social networks, i.e. business, friendship and family networks, from a multi-rational perspective and considers how they influence the behaviour of family businesses.

There is evidence that entrepreneurial behaviour, culture, connectivity and social milieu are linked (Gionetti and Simonov, 2009; Pachuki and Breiger, 2010). Family businesses in particular behave differently from firms without a substantial family component, due to the distinct but overlapping influences of family, business and friendship relationships (Vought et al., 2008; Gupta and Levenburg, 2012; Classen et 
al., 2012). Indeed, it can be argued that in general families and their businesses are inextricably intertwined and hence differ from other SMEs (Aldrich and Cliff, 2003). Three concepts are used in this paper to help analyse networks in business families: the notion of 'family'; multiple rationalities that influence decisions; and social networks.

First, in exploring the difference between family businesses and other SMEs, a variety of theoretical perspectives have been applied, often without greatly adding to clarity (Pearson et al., 2008). One exception is the concept of familieness, defined as 'the resources and capabilities related to family involvement and interaction' (Chrisman et al., 2005, p468). While the networks of a business form an integral part of these resources and capabilities, Seaman et al. (2014) have argued that the family influence changes the way in which the networking process develops, due to the varying influences of the family, business and friendship networks, and hence a multi-rational approach is useful in providing new insights into the analysis of networks that surround the family business. A multi-rational approach is defined here, as an acceptance that family rationales, business logic and the needs of the family business are distinct from each other but intertwine; with different rationales taking precedence at different times and in different circumstances.

While the concept of family business and the challenges they face, alongside the contexts within which they operate, has been documented in the literature using the individual family businesses as the unit of analysis (Poutziouris et al., 2006), networks do not feature significantly when the major research themes within family business are summarized (Klein and Kellerman, 2008). Despite a variety of approaches to network research, most work is underpinned by a mono-rational approach that considers solely 
either the needs of the business or the social context (O'Donnell, 2001). This distinction exists despite an acknowledgement that social networks also play a role in entrepreneurial behaviour (Jenson and Greve, 2002; Lofsten, 2016) and that balancing family and business priorities is a key to the strategic development of family businesses (Sharma et al., 1997).

Second, rather than decision making within a family business being influenced by a single rationale (i.e. from the perspective of business needs), there may be several distinct rationales that co-exist, each based upon the separate influences, rationales and logics of the family, business and friendship networks (Poutziouris, 2009; Seaman et $a l ., 2014)$. Originally rooted in the literature surrounding the development of business strategy (Hall, 2002), concepts of multiple rationalities have developed from earlier discussions within a family business context that looked at the background to individual business decisions and considered that the business-logic underpinning many decisions appeared to be irrational (Poutziouris, 2009; Wang and Poutziouris, 2010). Hall (2002), however, argued that the strategic decisions being taken were not in themselves irrational; rather that the nature of the decisions being made reflected the multi-rational nature of decisions taken where a family and the businesses within that family intertwine reflecting the critical importance of balancing the family and business needs.

Third, social networks, defined as the social structures made up by people (nodes) connected (tied) to other people by different types of dependency, have been extensively researched and operate on a number of different levels, from individual families to nations and beyond (INSNA, 2010). The ties that link individuals may be weak (where people only meet infrequently and have a weak relationship to each other) 
or strong (such as good friends or relatives) (Granovetter, 1983) ${ }^{1}$. Both weak and strong ties may be useful to SMEs in different circumstances (McFadyen and Canella, 2004), and Lowik et al. (2012) argue that strong ties or 'bridging capabilities', between SMEs and others, allow them to acquire new knowledge that assists the development of new products, although a lack of internal resources can limit such links for SMEs. Dodd et al. (2015), however, argue that weak ties are more important for the growth of family firms, compared to other SMEs.

A family business can help overcome resource gaps through using multiple forms of networks and multiple internal participants in the SME (i.e. different family members). By using multiple networks the family may also influence the breadth of search for different types of partners or innovative ideas, although the fear of negatively affecting the family wellbeing can mean that family businesses have less diversified networks than other SMEs (Gomez-Mejia et al., 2007). In a study of 4,000 businesses in Belgium and the Netherlands Classen et al. (2012) found that more 'open' (better educated CEOs or a greater share of managers not from the family) family businesses had wider positive search breadth. This paper extends this as such networks are disaggregated into different forms of network, family, friendship and business networks, which reflect the multiple rationalities perspectives discussed above. While the concept of multi-rational approaches hase generally been applied to strategy, here it is applied to networking, given the manner in which the business and social aspects of networking overlap and intertwine even for individuals. Within the current paper the concept, and discussion that surrounds different types of network within family businesses, is explored and

\footnotetext{
${ }^{1}$ Business networks have been defined as a series of interconnected business relationships (Prenkert and Hallen, 2006).
} 
illustrated by a case study. By focusing on one UK business family, with an established track record in business start-up, exploring the networks that surround that family, we analyse the manner in which family, friendship and business networks interact and influence the development and behaviour of one or more businesses.

The next section sets out definitions and the concepts of family businesses and business families. Section 3 presents the methodology. Section 4 analyses the case study covering the family business profile and the current pattern of business ownership. This is followed by conclusions.

\section{Family business definitions}

Family businesses form a cornerstone of the economies of most developed countries and appear to provide a degree of community and social stability (Poutzioris, 2006; Kets de Vries, 2007, pxiii), while the family in business, operating more than one business, may create a unique organizational form (for a review see: Klein and Kellerman, 2008). However, definitions of a family business are the subject of debate; indeed Sharma et al. (1996) and Chua et al. (1999) identified no fewer than 34 different definitions within the literature (Getz et al., 2004), albeit with some common themes. The definition adopted within this paper is the self-definition taken from Getz et al. (2004, p5):

'a family business is any business owned or operated by a couple or family where the business owners themselves perceive it 
to be a family business'.

Exploring family business networks and the manner by which individuals within a family business access and contribute to different networks (Kets de Vries et al., 2007, p43-48) forms, therefore, a useful step towards understanding more about the manner in which businesses network, learn and develop. This paper therefore considers both several family businesses within the business family.

\section{Methodology and context}

The exploration of social and business structures such as networks is often explored using case studies, in part because of the depth of data which can be collected (Litz et al. (2001; Zeleny, 2001; Hoang and Antoncic, 2003; Smith et al., 2013). The current research comprises a case study of a business family, with an extensive track record in a number of businesses, business sectors and business environments. The husband and wife were interviewed regarding networking using a semi-structured questionnaire, to identify their main network ties and the manner in which their network had developed historically. Their responses were mapped initially individually and later as part of the wider family pattern and validated via a series of follow-up interviews that considered in depth individual mappings, their accuracy and additions. Hill et al. (1999) looked at the transition from near-dependence on social networks to more focused business networks as firms develop. The rationale for the decision to use a case study methodology is therefore based primarily around the richness of network data, alongside the acknowledged role of case study research in the development of theory (Dooley, 2002). 
Pachuki and Breiger (2010) when summarizing the work of Friedland (2009) state that “individuals live across institutional fields", and situations and organizations involve more than one logic of practice; and some of these logics are co-implicated. This paper seeks to help understand how these partially interdependent, partially divergent logics can be differentiated, bridged, contested, or mediated. That individuals live across different institutional fields involving more than one logic of practice is a key tenet of multi-rational theory and we apply this to the multi-rationalities of family, friendship and business. Hence a purposeful sample of one case study multi-generational, family business with involvement in a variety of networks, including international links, was chosen from a wider research sample.

As discussed earlier, this study of social networks is not restricted to formal business networks but seeks in addition to explore the family and other social ties such as friends and acquaintances (termed family and friendship networks in this paper) which form part of the business family environment. Each member of the family interviewed described their major sphere of input/influence within different businesses and identifies the networks they accessed. The manner in which the individual perceived their networks to contribute to the business was explored, before the individuals identified whether any other members of the family accessed each of the networks or were aware of links between the individuals identified. During the second part of the interview the key individuals whom individual business owners perceived as important contacts were identified alongside the type of expertise they brought to the relationship, whether specialist professional, local community or family business experience. Notes were kept to identify whether the individual contacts named at this stage are also part of the family. 
While exploring networks within the family, each individual interviewed identified the key people whom they talked to within the family and identified whether those discussions tended to be family-based discussions, business-based discussions or whether they considered the family member a friend or confidant in a more personal sense. Following initial mapping and graphic representation of the business history and current situation, a series of follow up interviews allowed individual members of the family to comment on the mapping both individually and (subsequently) as a matter for discussion between parties. The networks drawn are based on the analysis of the interview data, using UCINET (Borgatti and Everett, 2002) and NETDRAW (Borgatti, 2002). To examine the different multiple rationalities of a business family, the business, family and friendship networks are analysed separately. The subsequent multi-rational mapping, by incorporating all three dimensions, assists in the identification of previously unnoticed ties. In addition the analysis considers changes in the ties over time.

\section{Family profile:}

\section{Identity and family structure}

The family used for illustration is composed of a husband and wife with three, adult aged, children. Both husband and wife run separate businesses, developed on the basis of a number of other businesses within the family history. The primary business within which the wife is involved is an accountancy and tax advisory and bookkeeping business catering largely to SME businesses in a small town near a large city. The husband's primary current business involvement is with a manufacturing firm making 
electronic control devices for sale to a diverse group of companies involved in the management of properties worldwide.

The case study business family is located within a rural area of the UK near a major city. As in many other countries, SMEs and family businesses are relatively evenly spread across the geographic population whilst major companies are far more likely to be found in the areas of greater population density (Scottish Government, 2007). At the time of the case study the parents have been resident in the region for just over 20 years. One child is a student staying at home during holidays but in student accommodation in another major city during term time. The other two children have left home - one based in London working in the financial sector, and the other having recently graduated and being employed in a different major city in a temporary post within the tourism sector.

\section{Business history of the family}

An extensive past record in a wide variety of businesses is both evident within the family and forms part of the rationale for their choice as an appropriate case study. Originally re-locating to his current region for a job with an external employer, the husband was subsequently made redundant but the family was settled within the local community and chose to stay in the area. Whilst work was forthcoming thereafter, the short term nature of the contracts created a general lack of security. When one short term contract ended as his employer was failing, the husband was prompted to take over one contract from the portfolio he had worked on for that company. Important at this stage in the family and business development were two factors: the arrival of babies which made relocating unattractive and a past record in business in North America 
which gave an initial perception that being in business on one's own account was both possible and desirable. Contrasts with starting-up a business in North America soon emerged, however, and illustrated the importance of cultural perspectives on one key network link:

'We lived in [North America]for ...... years and that's what started us off on wanting to run our own business .......the culture is better there, getting money is easier. There's more element of trust ...... one thing I found is that if you wanted money (in the UK) you might get a little bit of money for marketing only if you used a recommended consultant and you only get $50 \%$ of the money ....... it's not any help ...... I worked with (a regional business support agency) and the set up was scandalous to be honest.'

The successful development and sale of this initial business, involving private equity investors and a change in the internal culture of the business (Scholes et al., 2007), created a situation where the family were keen to continue in business but with a much clearer vision of the form that might take. A distinct preference for operating in an area where those in control of the day-to-day operation also had decision making authority links to agency theory (Oswald et al., 2009) but was perceived here as a lifestyle choice, which it was assumed would also benefit business performance. Further, there is awareness within the family of issues surrounding the need to resist market control and to build private sources of capital, customers and support ( $\mathrm{Ng}$ and Keasey, 2010). Networks appear vital, albeit on a very informal and ad hoc basis:

' .......... we (a group of local entrepreneurs) didn't meet every week down the pub. We weren't great, great friends from long ago but ......... because we were all of us .... into inventing and entrepreneurial things that we often met up and talked of projects that we were doing .......'

Husband

This evidence is consistent with earlier work cited above (such as Aldrich and Cliff, 2003) that indicates that access to networks at start-up is vital not only in terms of 
equipment, space and resources but also - and perhaps more importantly here - in terms of cultural acceptance of entrepreneurship.

The push (for example, difficulty in getting a job elsewhere) and pull (for example, the desire to be one's own boss) factors influencing the decision to start and remain in business are highlighted by comments on the difficulties of returning to being an employee with an outside employer after a time running an independent business:

'........ And you can't, when you've been running your own business, people just won't employ you. They just think you're some kind of maverick maniac who is going to come and take over the business or something. And you can get very paranoid about it. So, it's quite difficult so you are basically faced with starting something completely new again.

Husband

Interesting there is similarity with research looking at the push and pull factors and barriers to employment influencing business start-up and ownership in minority ethnic communities and the indication that many similar factors may apply in mainstream business communities. Business and personal history, especially issues that surround business take over and the role of the venture capitalists, are key here and demonstrate both a substantial area of past business learning within diverse networks and a determination within the family to avoid past mistakes made within one business but, crucially, with the learning transferred to subsequent businesses via family 'memory'.

\section{Current pattern of business ownership}

In defining the current case study as containing several family businesses, three factors play a major role: the involvement of at least two members of the family on a daily basis; the self-definition of the operations as family businesses; and the perception that succession might come from within the family itself, although this was neither clear nor 
formalized at the time of the case study. Cultural, social and psychological factors also influence the succession process (Gundolf et al., 2013) and notable was the view:

'.... I thought (her son) might (come into the business), but not for a number of years.........he could take over from me and run the (accountancy) business, but maybe if he got married, had kids and this would appeal more - to run the business ..... it's always going to be a small family business ...'

Wife

This pattern of a family, combined with business development and management, who operate in different ways at different times and in different businesses suggests the focus should be a business family rather than a family business (Kenyon-Rouvinez, 2001; Dhaliwal, 2006). In this context a tentative definition of a business family is of a family with a distinct and significant pattern of entrepreneurial behaviour alongside patterns of business start-up and development, with an important element of internal family business related interaction and support during those processes.

Examining the manner in which a business family operates and the networking patterns that develop, considered here within a framework of multiple rationalities, forms the basis for the current study. One quote perhaps helps to clarify this distinction; talking of the decision to develop new businesses after the partially successful sale of the original family enterprise, the comment was made:

' ........ so we decided, what we would do, we would set up three new companies .... So we did ....... We registered three new companies and we had only the vaguest idea what we were going to do with the companies at the time ........ and it will be a 'mom and pop' business and we'll not have any outside investors, no bank loans, nothing ....... so it all sounds a bit of a jumble ....... But we did that deliberately so we'd have multiple revenue streams .....'

Husband 
The business structure around the family is summarized in Figure 1. In this figure the ties represent reported ties drawn from interview data. The strength of the ties is not indicated, but the existence of a tie important enough to be recorded is.

\section{Insert Figure 1 about here}

This structure stands in contrast to entrepreneurship research that considers the role of unpaid labour in co-preneurial and family businesses (Blenkinsopp and Owens, 2010), prioritizing instead reciprocity of support within the business family context. This reciprocity of support - across different businesses, sectors and decades - is key to the concept of business families and their role in facilitating business and enterprise. Also of interest is that, while the role of case study research surrounding the sale and recreation of businesses within a business family context has been highlighted, far less research has considered the business family in relative stasis, i.e. not undergoing such radical changes.

\section{Networks within and around the family and their businesses}

An initial mapping of the business network showed both the formal aspects of the business network and the less formal contacts highlighted during the course of the interviews. The relative simplicity of the business network is notable and stands in direct contrast to the subtleties of the interview data. Indeed, a number of key themes became apparent from the interviews which are relevant to the principles of multiple rationalities, notably the dynamic and ever-developing nature of contacts and the difficulties in quantifying or predicting the longer-term importance of a new contact. Similarly, the limited scope to follow all the contacts up was noted alongside the 
perceptions that some element of judgment about the relative importance of a contact was required and that a better forum for local business networking would be useful.

In contrast the friendship network includes a number of individuals who are in business in their own right, illustrating network ties into the local community. Key to their inclusion in the friendship network is that the primary affiliation highlighted within the interview was friendship. Finally the immediate family network, includes a number of individuals, some currently resident in the family home and others not. This is the family network described at interview and considered as the 'primary' family network.

Each of the three networks are interrelated, as shown in Figure 2, which reflects the additional ties visible when the three rationales of family, friendship and business are considered together. By mapping the three broad groups of networks together, additional ties become apparent, such as the ties between the children and their parents business network. For instance, there are three ties between local business family friends which cross boundaries between network rationales. Two of these ties are between the friendship and the business network. One of the ties (between the friendship and the family rationales) identifies a link between the third adult child (Child 3) and a local business family friend. This child, who is involved in tourism, also has links with the local business community and the local business development unit, revealing strong multi-rational connectivity through spanning all three rationales in the network.

\section{Insert Figure 2 about here}


Child 1 also bridges the family and business rationales with support from parental ties with venture capitalists (father's link, called husband's link henceforth) and a major accountancy firm (mother's/wife's) link). Also the husband's business contacts are local family friends as well as having ties with the wife's charity contacts, a duality in network ties which extends both to the network of entrepreneurs with which the husband has ties of friendship and the contacts with whom the wife works in local charities on an unpaid basis, but which nevertheless draws on her professional accountancy knowledge. Extending the analysis to a multi-rational approach, therefore, allows a number of links to become apparent which were present within the interview data but less visible when the separate rationales were individually mapped.

Figure 2 combines the separate rationales occupied by the individuals and parties concerned. The additional links noted within the networks illustrate an acceptance by family members that individuals within their personal networks play different roles in different circumstances, which is acknowledged by the interviewees when they describe the development of their networks over time. We argue that the family in business and the long term development of networks are central to understanding the business family, rooted within a community and unlikely to undertake major geographical re-location. Where a family is based within a community on a long-term basis, some individuals move through the lifecycle as part of the network. As individuals reach maturity, develop careers and experience, their contribution to the network is likely to change. In addition to principles of multiple rationalities, therefore, the longitudinal aspect of networks is important in any analysis of the business family. 
An extension of this process includes the potential identification of structural holes and freedom from redundancy within the relatively close-knit networks of a small community. In social network analysis, Burt (1992) defined a "structural hole" as the lack of ties between contacts of an actor who tend to be connected only through ties to that actor (i.e. the contacts are not directly linked to each other except through that actor). Pachuki and Breiger (2010) introduce the related concept of "cultural holes" according to which certain types of local mediation in network structure serve to span the boundaries between networks and culture. More precisely cultural holes are contingencies of meaning, practice, and discourse that enable social structure and structural holes. The effective sizes of the husband and wife egonetworks ${ }^{2}$ (20.0 and 20.9), as measured by UCINET (Borgatti and Everett, 2002), are large and hence rich in potential for business expansion. Examples here lie in the business contacts which the husband retains from his time living and working in North America and the ties with charitable organizations retained by the wife. Whilst the historical move to a different country is relevant here and touches on the potential role of expatriate community as potential bridges within networks, the existence of and reasons behind structural holes within a close-knit rural community would in itself merit attention. Having ties with businesses, which do not themselves have ties with each other, can be strategically beneficial in opening up opportunities for further business (Burt, 1987 1992). The emergence of such ties within a multi-rational context opens up additional business opportunities as access to a broader network is gained.

\footnotetext{
${ }^{2}$ The effective size of an ego-network is the extent to which it is free from redundant ties. If I have a friend who is also a friend of my friend then the tie I have is redundant from a business point of view since my friends can share knowledge with each other to my disadvantage. It should be noted that the interviews were predominantly with the husband and wife so that their egonets are described in most detail and are expected to be the largest.
} 
The emergence of structural holes in the adult children's networks, which are significantly inherited from their parents, creates potential for the development of entrepreneurial initiative, which Child 3 and Child 1 exploit through the creation of ties crossing business, family and friendship rationales (Figure 2). Child 3 emerges as the least constrained of the siblings with the largest effective egonet size of 4.8 , with Child 1 having size 3.9 and Child 2 having size 1.0. We argue that the family acts as a bridge in more than just the narrow sense of spanning structural holes, since ties crossing rationales have a richer connotation from the basic definition of a bridge (i.e. a bridge as a tie which leaves no path between the nodes it connects when it is removed). Child 1 and Child 3 illustrate this through the formation of both friendship ties with a local business family friend and the local business community as well as business ties with venture capitalists and the local economic development unit. Although such ties may not be bridges in the formal sense from a family perspective, since they are almost all already bridged by parents, they encourage the exploration of new ties and bridges to the business community through structural embedding in family and friendship networks. From an individual perspective, such ties appear as bridges, although this illustrates the additional information gathered from taking a family perspective.

The structure of the networks can be more closely analyzed through the use of the structural block model routine in UCINET. The concept of a structurally equivalent block applies to a group of individuals that have similar relationships with the same or other individuals in the network. In this context structural similarity may stimulate a competitive orientation in which individuals are attentive to each other's status and interests (Burt, 1987). The analysis identifies three blocks. The first consists of the husband and wife as might be expected. The other two blocks are focused on two 
individuals; one of whom is Child 1 and the other is Child 3. This supports the argument set out here, which puts the husband and wife at the centre of family/business/friendship concept and maps the formation of ties crossing rationales.

\section{Longitudinal development of networks within and around the family}

An important issue, generally neglected in the literature, is the development of networks over time. The evaluation of longitudinal network development within a series of interviews in real time is not straightforward, but some key patterns emerge from the present study. One facet surrounds the small, core group of entrepreneurs who have remained a relatively constant part of the network (observable currently but also part of the historic network) whilst others have joined or left the network (Figure 3).

\section{Insert Figure 3 about here}

A second pattern can be observed in the on-going development of a network of charity and community contacts which are not explicitly business related but which are likely to contribute in terms of business profile within the local community and to offer informal advice and intelligence. The charity contacts in particular merit mention as they have primarily been developed by the wife and offer a distinctive addition by one individual to the multi-rational network space. Key also is the manner, which is illustrated in Figure 3, of how changes in the family network affect the business network and vice versa. This can range from the expansion in network ties associated with the raising of children in the community (e.g. families with similarly aged children) to the business contacts that may become mentors or indeed business contacts for those children as they grow up and enter the workplace. Over time, different generations of 
the family helped fill some of the structural holes in the family, friendship and business networks.

If the evidence presented in this longitudinal analysis is added to the earlier evidence of interaction between the family, friendship and business networks, the potential importance of further study to examine in greater depth longitudinal business family network development becomes apparent. Additional, clear evidence of the multiple rationalities in the manner in which charity-based and social networks influence business and vice versa on an on-going basis was also observed as part of the social networks within the community. An example of this is the on-going development of friendships from network ties originally created in the business rationale.

\section{Conclusions}

A main conclusion of this paper is that using the concept of a multi-rational approach leads to a fuller analysis of influences on family business development and behaviour. This includes the identification of a number of links, and interactions between the family, social and business networks, which were present within the interview data but were not as clearly visible when the separate rationales were mapped individually. The paper considers the relationships between business, friendship and family social networks from a multi-rational perspective, using a family in business to illustrate some of these effects and showing how these networks develop over time and influence the behaviour of the family in business. It starts from the premise that local economic development is often dependent on smaller businesses, owned and managed by families and benefiting from the social networks that families in business can access. 
Developing a deeper understanding of the manner in which those networks operate offers potential benefits to those directly engaged with local economic development, in particular around the manner in which smaller businesses are encouraged to develop their networks. By considering the interaction between family, business and friendship networks, the paper provides an initial exploration of the topic and contributes to research based evidence around the manner in which smaller businesses can best be encouraged along this path. Four main conclusions from this exploratory analysis can be drawn.

First, accepting that networks are important for business development (Lofsten, 2016) and that rural businesses may as a consequence of the geographic location have limited access to networks (Kapasi and Galloway, 2016), the importance of interaction between the family, business and social networks is clearly demonstrated. This approach offers support for a multi-rational perspective (Seaman et al., 2014), but also suggests that network development for smaller businesses may best be approached by encouraging smaller businesses to consider the potentially useful network ties that may exist within the family, business and friendship networks.

A second conclusion highlights the importance within the business family of a track record of business start-up and development. It identifies clear evidence that multiple rationalities, in the varying forms and influences of family, friendship and business networks, play a part in both the current operation and the longitudinal development of networks. The categorization of the network into ties associated with business, family and friendship enables the identification of cross-rationale ties and structural features 
associated with entrepreneurial activity, but the importance of the development of the network over time should not be overlooked.

A third conclusion is around the existence of distinct structural holes, or gaps, within the networks of the family in business. Our structural analysis identifies three structurally equivalent groups each associated with a group of individuals that have similar relationships with the same or other individuals in the network. The groups consist of the husband and wife, the third adult child and the first adult child respectively and illustrate the way in which the structurally equivalent friendship and business ties of the husband and wife complement the network structure. Specifically, he wife has a strong business network of trade organizations and former business partners while the husband has ties with American businesses and businesses that are also family friends, in addition to being linked to charities through the wife. The children also have emerging structural and multi-rational roles in the network, both through the network ties they themselves develop but also through the increased community engagement (and hence additional network ties) their parents experience associated with raising a family in a relatively small community. The emergence of structural holes in the adult children's networks, which are significantly inherited from their parents, also creates potential for the development of entrepreneurial initiative through cross-rationale bridging over time. The exploratory results in this paper support the view that a family business with highly educated members and a history of strong international links, can help overcome potential resource gaps through using multiple forms of networks and multiple internal participants in the SME (i.e. different family members). 
Hence, it is argued here that families can act as bridges in more than just the narrow sense of spanning structural holes. The reality is much richer when viewed at the cultural frontiers of family, friendship and business. It is argued that a manifestation of 'familieness' may be the manner in which family businesses use networks and that the use of multi-rational perspectives offers further insights into the behaviour of family businesses and business families, which differ from those of other small businesses.

The fourth conclusion is that the concept of a business family (a family organization where entrepreneurial development and business activity are part of the everyday modus operandi) is a useful basis for future research which focuses upon network interaction among family businesses.

Further research that focuses on longitudinal mapping could be used to explore business families and the manner in which they act as an enterprise nexus for the long term benefit of individuals, families and communities. There are also potential links to stewardship theory: a parallel can be drawn between theories that suggest individuals may act in a manner primarily driven by concern for the business (Davies et al., 2010) and that they may develop networks for a variety of different reasons. Processes of influence and selection could also be uncovered by studying the dynamic interplay between changes in the business, family and friendship networks and the behavioural and entrepreneurial activity of the individuals and companies (Steglich et al., 2010). Longitudinal research also offers potential for the profiling of business families within a geographic area and impact analysis of future interventions that aim to support family businesses, business families and hence communities. The pattern of on-going network 
development observed in a relatively closed community adds substantially to the weight of evidence in favour of multi-rational approaches to analysing networking.

In summary, if business families form the basis for a broad range of entrepreneurial developments then the manner in which they access, use and develop networks is important. Using a multi-generational, longitudinal network analysis, and identifying structural holes in the networks, provides useful insights into the behaviour and development of family firms. The theory of multiple rationalities as a theoretical perspective through which the actions of the family in business may be better understood, should also improve our understanding of the development and behaviour of family businesses.

\section{Acknowledgement}

The authors would like to thank the business that kindly contributed to this study.

\section{References}

Aldrich, H.E. and Cliff, J.E. (2003). "The Pervasive Effects of Family on Entrepreneurship: Towards a Family Embeddedness Perspective", Journal of Business Venturing 185 573-595

Blenkinsopp, J. and Owens, G. (2010). "At the Heart of Things: The Role of the Married Couple in Entrepreneurship and Family Business", International Journal of Entrepreneurial Behaviour and Research 2 357-369

Borgatti, S.P. (2002). NetDraw Software for Network Visualization. Lexington, KY: Analytic Technologies

Borgatti, S.P., Everett, M.G. and Freeman, L.C. (2002). UCINET for Windows: Software for Social Network Analysis. Harvard, MA: Analytic Technologies

Burt, R.S. (1987). "Social contagion and innovation: Cohesion versus structural equivalence", American Journal of Sociology 926 1287-1335

Burt R. (1992). Structural Holes Cambridge, MA: Harvard Univ. Press 
Classen, N., A., Van Gils, Y. Bammens, M. Carree (2012). "Accessing Resources from Innovation Partners: The Search Breadth of Family SMEs", Journal of Small Business Management 50 191-215.

Chua, J., Chrisman, J. and Sharma, P. (1999). "Defining the Family Business by Behavior", Entrepreneurship Theory and Practice 234 19-37

Chrisman, J.J., Chua, J.H. and Pramodita, S. (2005). "Trends and Directions in the Development of a Strategic Management Theory of the Family Firm", Entrepreneurship Theory and Practice 295 555-576

Davies, H. H., Allen, M.R. and Hayes, D.H. (2010). "Is Blood Thicker Than Water? A Study of Stewardship Perceptions in Family Business", Entrepreneurship Theory and Practice 346 1093-1116

Dhaliwal, S. and Kangis, P. (2006). "Asians in the UK: Gender, Generations and Enterprise", Equal Opportunities International 25 292-108

Dodd, S., Anderson, A. \& Jack, S. (2015). "Networking and entrepreneurial family firms", in K Randerson, C Bettinelli, G Dossena \& A Fayolle (eds), Family entrepreneurship: rethinking the research agenda. Routledge, London

Dooley, L.M. (2002). "Case Study Research and Theory Building", Advances in Developing Human Resources 43 335-354

Fayolle, A. (ed.), Jack, S.L. (ed.), Lamine, W. \& Chabaud (2016) Entrepreneurial process and social networks: a dynamic perspective, Edward Elgar, Cheltenham

Fletcher, D. (2002). "A Network Perspective of Cultural Organising and Professional Management in the Small Family Business", Journal of Small Business and Enterprise Development 94 400-415

Friedland R. (2009). “The endless fields of Pierre Bourdieu”, Organization 166 1-31

Getz, D., Carlsen, J. and Morrison, A. (2004). The Family Business in Hospitality and Tourism CABI Publishing Cambridge MA.

Giannetti, M. and Simonov, A. (2009). "Social Interactions and Entrepreneurial Activity", Journal of Economics and Management Strategy 18 665-709

Gómez-Mejía, L. R., K. T. Haynes, M. Núñez-Nickel, K. J. L. Jacobson, and H. Moyano-Fuentes (2007). "Socioemotional Wealth and Business Risk in FamilyControlled Firms: Evidence from Spanish Olive Oil Mills", Administrative Science Quarterly 52, 106-137

Granovetter, M. (1983). "The Strength of Weak Ties: A Network Theory Revisited", Sociological Theory 1 201-233 
Gronum S., M. L. Verreynne, T. Kastelle (2012). "The Role of Networks in Small and Medium-Sized Enterprise Innovation and Firm Performance", Journal of Small Business Management 502 257-282

Gundolf, K., Meier, O. and Mossonier, A. (2013). Transmission of Family Businesses in France. International Journal of Entrepreneurial Behaviour and Research 191 53-71

Gupta, V. and Levenburg, N. (2012). "Cultures, ideologies and Family Businesses", Journal of Family Business Management 21 57-75

Hall, A. (2002). "Towards an Understanding of Strategy Processes in Small Family Businesses: A Multi-Rational Perspective" In: Fletcher, D.E. (ed.) Understanding the Small Family Business Pp. 32-45 Routledge, London and New York

Hill, J., McCowan, P. and Drummond, P. (1999). "The Development and Application of a Qualitative Approach to Researching the Marketing Networks of Small Firm Entrepreneurs", Qualitative Market Research: An International Journal 22 71-81

Hoang, H. and Antoncic, B. (2003). "Network Based Research in Entrepreneurship: A Critical Review", Journal of Business Venturing 182 165-187

INSNA (2010). The International Network for Social Network Analysts http://www.insna.org/ Accessed 3/10/2015

Jensen, J.I. and Greve, A. (2002). "Does the Degree of Redundancy in Social Networks Influence the Success of Business Start-Ups?" International Journal of Entrepreneurial Behaviour and Research 85 254-267

Kapasi, I. and Galloway, L. (2016) Motivations and Mitigating Business Limitations in Scottish Rural Home-Based Businesses, Local Economy 313 377-392

Kets de Vries, M., Carlock, R.S. and Florent-Treacy, E. (2007). Family Business on the Couch: A Psychological Perspective Wiley, New York

Kenyon-Rouvinez, D. (2001). Family Business - Key Issues. Palgrave McMillan, New York

Klein, S.B. and Kellerman, F.W. (2008). "Guest Editorial: Understanding the NonEconomic Motivated Factors in Family Firms - An Introduction”, Family Business Review XXI 2 121-125

Litz, R.A., Kleysen, R.F. (2001). "Your old men shall dream dreams, your young men shall see visions: Toward a theory of family firm innovation with help from the Brubeck family", Family Business Review, 14 4, 335-351

Lofsten, H. (2016) "New Technology-Based Firms and Their Survival: The Importance of Business Networks and Entrepreneurial Business Behaviour and Competition", Local Economy 313 393-409 
Lowik, S., D. van Rossum, J. Kraaijenbrink, and A. Groen (2012). "Strong Ties as Sources of New Knowledge: How Small Firms Innovate through Bridging Capabilities", Journal of Small Business Management 50, 239-256

McFadyen, M. A., and A. A. Cannella (2004). "Social Capital and Knowledge Creation: Diminishing Returns of the Number and Strength of Exchange Relationships," Academy of Management Journal 47, 735-746

Ng, W. and Keasey, K. (2010). "Growing beyond smallness: How do small, closely controlled firms survive?” International Small Business Journal, Vol. 28(6), pp. 620 630

O’Donnell, A., Gilmore, A., Cummins, D., and Carson, D. (2001). "The Network Construct in Entrepreneurship Research: A Review and Critique", Management Decision 39/9 749-760

Oswald, S. L., Muse, L. A. and Rutherford, M. W. (2009). "The Influence of Large Stake Family Control on Performance: Is it Agency or Entrenchment?" Journal of Small Business Management, Vol. 47 (1), pp.116-135

Pachuki, M.A., Breiger R.L. (2010). "Cultural Holes: Beyond Relationality in Social Networks and Culture", Annual Review of Sociology 36:10.1-10.20

Pearson, A. W., Car, J.C. and Shaw, J.C. (2008). "Towards a Theory of Familieness", Entrepreneurship Theory and Practice 326 949-969

Poutziouris, Z.P., Smyrnios, K.X. and Klein B. S Ed. (2006). Handbook of Research on Family Business, Cheltenham: Edward Elgar,

Poutziouris, Z. P. (2009). Plural Rationalities in Family Business Strategy Paper to the ESRC Workshop on Family Business, the British Library, London

Prenkert, F. and Hallen, L. (2006). "Conceptualising, Delineating and Analysing Business Networks European”, Journal of Marketing 40 3/4 384-407

Scholes, L., Wright, M., Westhead, P., Burrows, A., Bruining, H. (2007). “Information Sharing, Price Negotiation and Management Buy-outs of Private Family-owned Firms”, Small Business Economics, 293 329-349

Scottish Government (2007). The Government Economic Strategy. Edinburgh: The Scottish Government

Seaman, C., Bent, R. and Unis, A. (2016). "The Role of Context. South Asian Family Firms in Scotland and the Succession Paradox", International Journal of Management Practice 94 333-343

Seaman, C., Bent, R. and Unis, A. (2015). "The Future of Family Entrepreneurship: Family Culture, Education and Entrepreneurial Intent in Scottish Pakistani Communities", Futures 75 83-91. 
Seaman, C., McQuaid, R. and Pearson, M. (2014). "Networks in Family Business: A Multi-Rational Approach", International Entrepreneurship and Management Journal, 103 523-537. doi: 10.1007/s11365-014-0297-4

Sharma, P., Chrisman, J and Chua, J. (1996). A Review and Annotated Bibliography of Family Business Studies. Boston MA: Kluwer

Sharma, P., Chrisman, J and Chua, J. (1997). "Strategic Management of the Family Business: Past Research and Future Challenges", Family Business Review 11 1-35

Smith, R., McElwee, G., McDonald, S., Dodd, S.D. (2013) "Qualitative entrepreneurship authorship: antecedents, processes and consequences", International Journal of Entrepreneurial Behaviour \& Research, 194364 - 386

Steglich, C., Snijders, T. and Pearson, M. (2010). "Dynamic Networks and Behavior: Separating Selection from Influence”, Sociological Methodology 40 329-393

Vought, K.L., Baker, L.T. and Smith, G.D. (2008). "Practitioner Commentary: Moving From Theory to Practice in Family Business Research", Entrepreneurship Theory and Practice 326 1111-1121

Wang, Y. Poutziouris, P. (2010). "Entrepreneurial risk taking: empirical evidence from UK family firms", International Journal of Entrepreneurial Behaviour \& Research, Vol. 16 (5), pp. 370-388

Zeleny, M. (2001). “Autopoiesis (Self Production) in SME Networks", Human Systems Management 20 201-207 


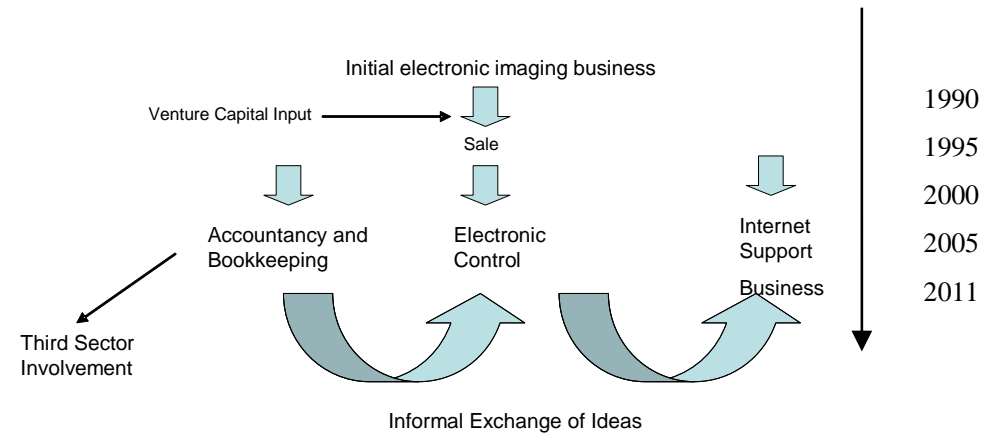

Figure 1 Family Business Genogram 


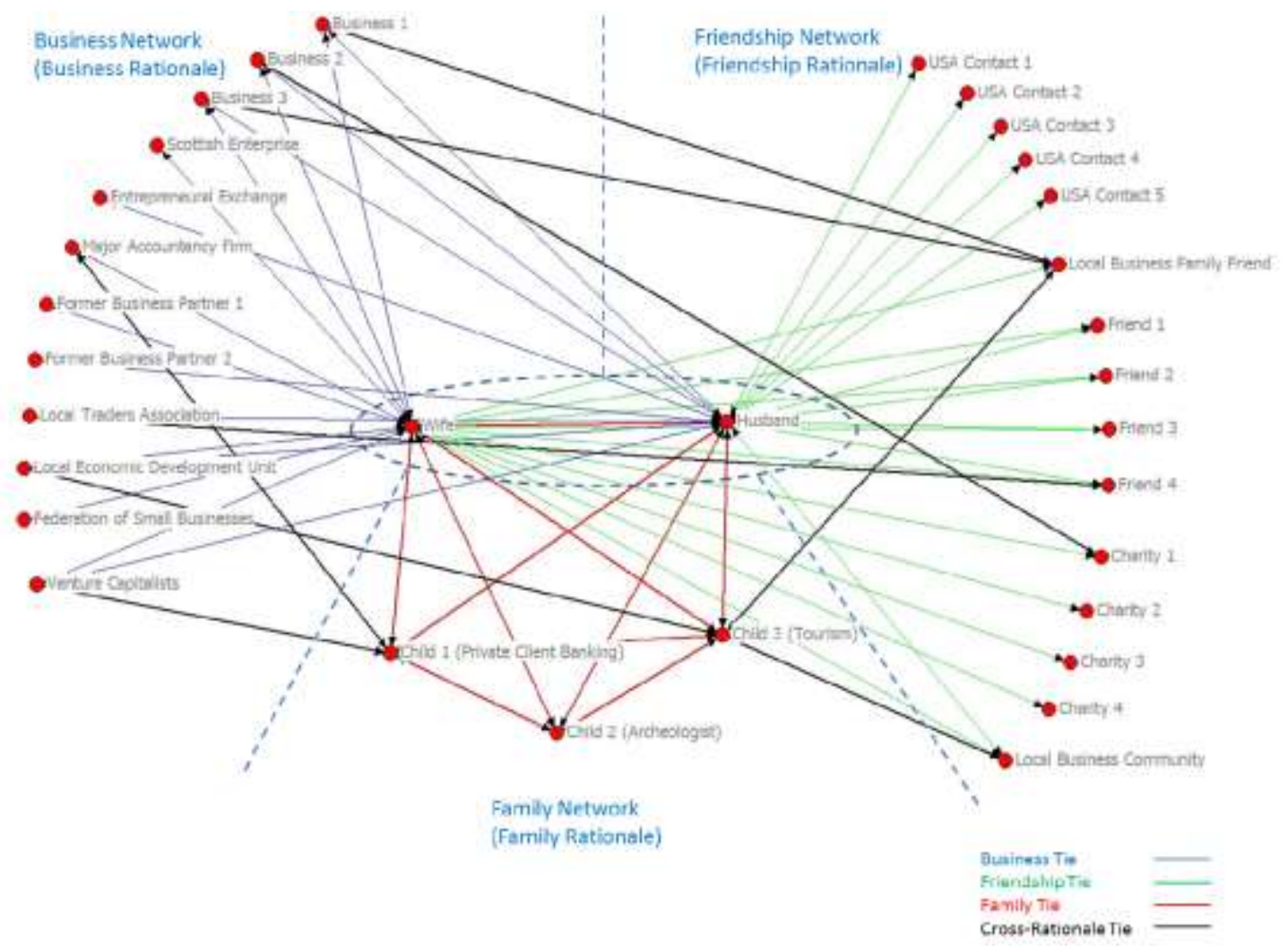

Figure 2 Multi-Rational Network Analysis indicating Reported Ties 
Longitudinal Network Development- Event List

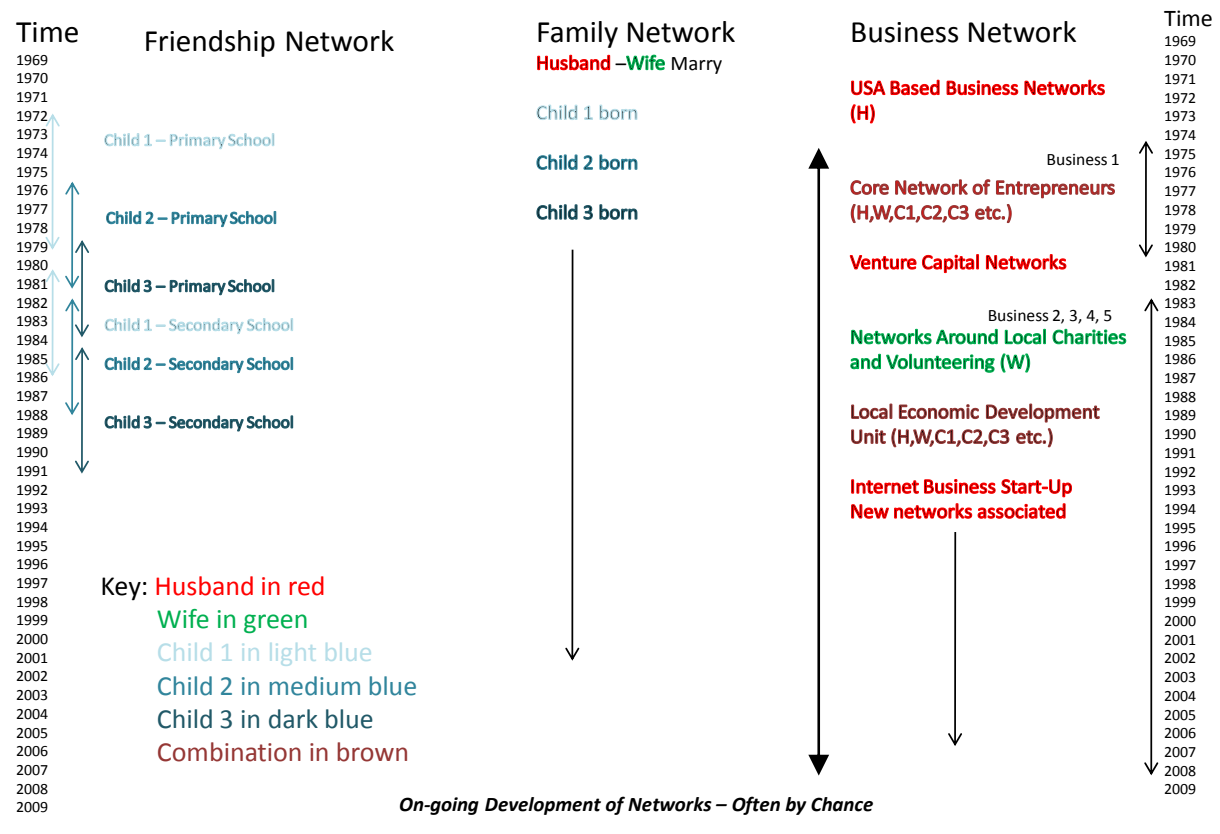

Figure 3 Longitudinal Network Developments - Event List 